\title{
WHAT DID THEY COOK? A PRELIMINARY INVESTIGATION INTO CULINARY PRACTICES AND POTTERY USE IN THE CENTRAL KOREAN PENINSULA DURING THE MID TO LATE HOLOCENE
}

\author{
Seungki Kwak and Ben Marwick \\ Department of Anthropology, University of Washington \\ skkwak@uw.edu,bmarwick@uw.edu
}

\begin{abstract}
This study attempts to understand prehistoric human subsistence in the Korean Peninsula through a preliminary organic geochemical analysis of archaeological potsherds. While traditional approaches focus on reconstructing the ancient pot functions or relative chronology, organic geochemical analyses on archaeological potteries endeavors to be precise about the types of food groups that were cooked or stored in a pot by attempting to identify the specific organic compounds trapped in the clay matrix. Since organic compounds are often preserved in direct association with archaeological pots, organic geochemical analyses have become an important method of investigation which archaeologists use to better understand the function of ceramic artifacts such as pottery and local diets. The sherd samples for the analyses in this paper were collected from the two prehistoric habitation sites located in the central part of the Korean Peninsula: KimpoYangchon site and Eupha-ri site. The main habitation period of the former is around $2800 \mathrm{BP}$ (B. Kim et al. 2013), and the latter site was occupied around $1800 \mathrm{BP}$ (Wang et al. 2013). We show that terrestrial animals are strongly represented in the organic residues, suggesting that views of a crop-dominated diet may be inadequate. Our results provide a critical clue to understand ancient subsistence of the central part of the Korean Peninsula.
\end{abstract}

\section{INTRODUCTION}

Tracing ancient human subsistence is a long-standing topic of archaeological investigation. Subsistence changes related to the emergence of agriculture always has been critical part of anthropological debate. This subsistence change was often described as a transition from hunter gathering to intensive agriculture. However, in many areas, scholars have only focused on how quickly or completely people abandoned wild terrestrial and marine resources after the introduction of domesticated plants (cf. Craig et al. 2011). Once the domesticated plants are introduced, the role of other food resources (e.g. animals) in ancient farmers' diet has been neglected.
In this study we focus on two sites in the central part of the Korean Peninsula, a region that contains a vast amount of archaeological materials related to subsistence change in the deeper past. This region has provided rich archaeological records documenting its general culture history. Its earliest known occupants were Paleolithic foragers dated as old as about 200,000 years ago (J. Kim et al. 2010). Low hills with gentle slopes embracing meandering rivers in this region were continuously occupied, and large habitation sites developed in this condition provide multiple lines of archaeological data.

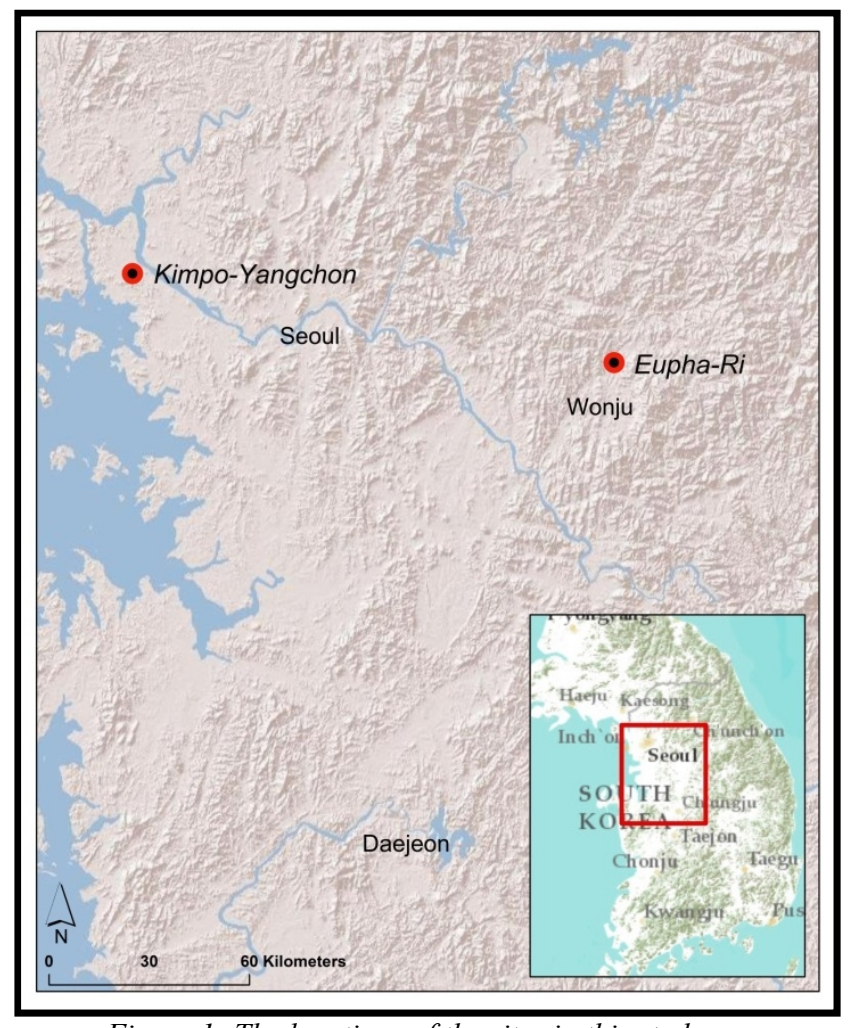

Figure 1: The locations of the sites in this study.

However, past efforts to reconstruct ancient dietary patterns in this area have been challenged by the high acidity of sediments (RDA 1988). Because of these acidic sediments, the direct examination of the remains 


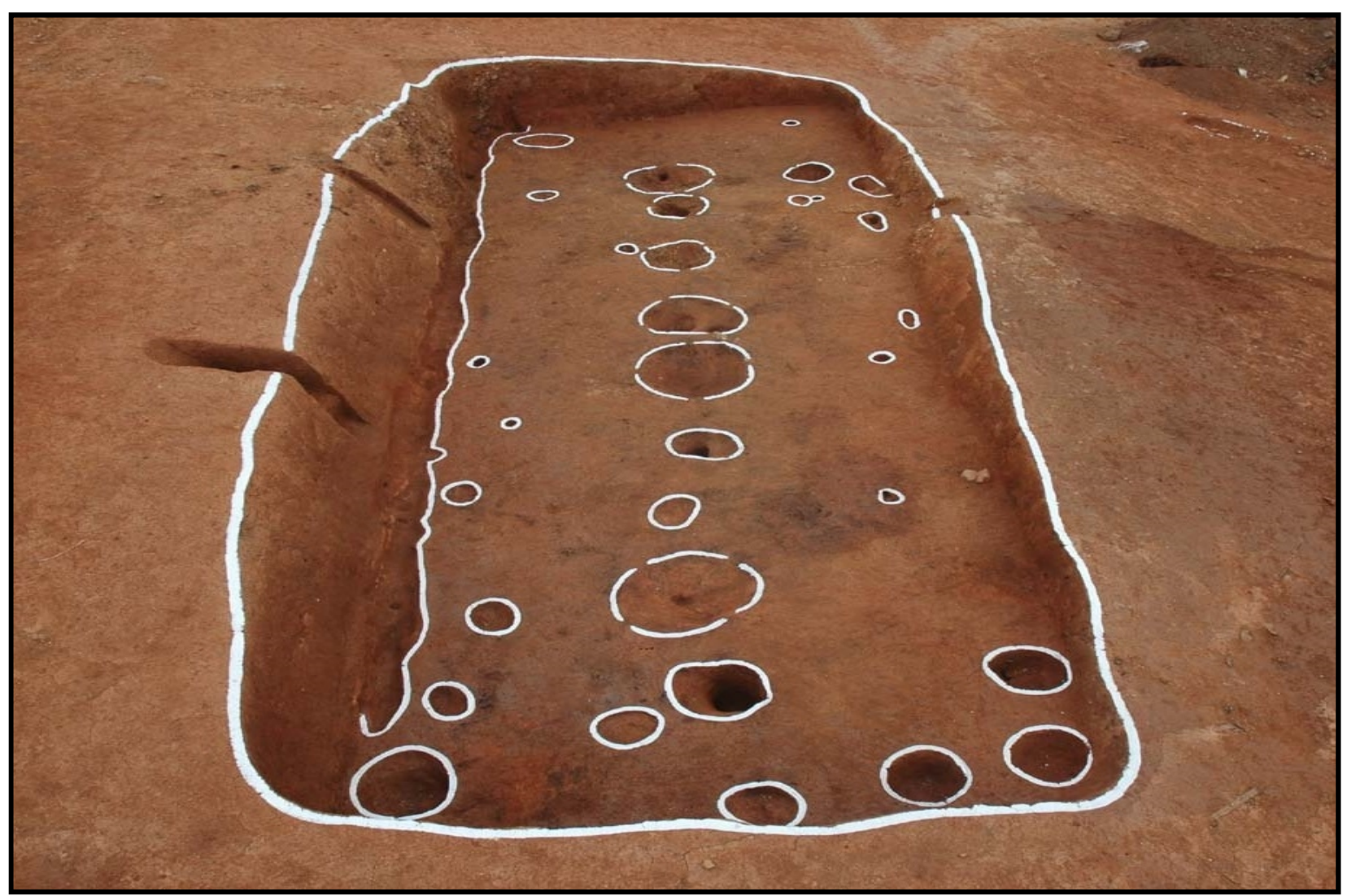

Figure 2: Longhouse-based households at Kimpo-Yangchon site (Kim et al. 2013).

of subsistence resources in the Korean Peninsula is limited to relatively special locations that provide better preservation of bone or plant remains such as cave, rock-shelters, or shell middens (K. Choy and Richards 2010; K. Choy et al. 2012). Organic geochemical analyses have great potential to overcome this limitation and provide a unique opportunity to understand the subsistence in major habitation sites through the direct examination of pottery: the most widespread material culture in prehistoric Korea. Organic geochemical analyses extract and identify the organic compounds that were absorbed into the fabric of pottery, and studies have shown that these compounds are relatively well insulated and preserved within the clay matrix (Heron, et al. 1991; Eerkens 2001; Eerkens 2005). Absorbed residues, unlike visible ones, cannot be removed from a sample by washing or scraping, and remain within the ceramic matrix of a pot until extracted by solvents (Reber and Evershed 2004:20). In this paper, we will report on our preliminary organic geochemical analyses of archaeological potsherds from two different habitation sites in the central part of the Korean Peninsula.

It is clear that intensive agriculture was practiced in the central part of the Korean Peninsula as early as around 3,400 BP (G. Lee 2003; 2011). Solid evidence of dry fields, irrigated paddies and harvesting tools has been found (T. Yoon and J. Bae 2010). During this period, many large scale inland habitation sites start to emerge. Most of these sites did not yield paleobotanical evidence and faunal remains due to post-depositional processes and the high acidity of the archaeological sediments. Due to these conditions, Korean archaeologists have not able to recover detailed information about the diet of ancient Korean farmers, and the main focus has been on harvested crops (B. Kim 2006; cf. G. Lee 2011). However, it is not entirely clear that ancient Koreans solely relied on harvested grains after the establishment of intensive agriculture. What other resources were procured along with those grains? This research will provide initial, but essential clues related to those questions with organic geochemical analyses.

Generally, organic geochemical analyses involve two different analytic approaches: Gas Chromatography - Mass Spectrometry and Compound Specific Isotope Analysis. The former is used for separation and identification of organic compounds within a potsherd, and the latter can be employed for the further isotopic analysis of specific compounds once they have been identified. If fatty acids such as C16:0 and C18:0 (ie. molecules organized around a chain of 16 or 18 Carbon atoms) are found in a range of different food products, isotopic analysis can further distinguish between their sources. Many recent organic geochemical studies on potsherds have successfully detected the presence of different types of food groups including animal fat, ruminant milk, marine resources (e.g. fish and mammals), fresh water resources, $\mathrm{C} 3$, and $\mathrm{C} 4$ plants through the combination of those two methods (Craig et al. 2011; Cramp 


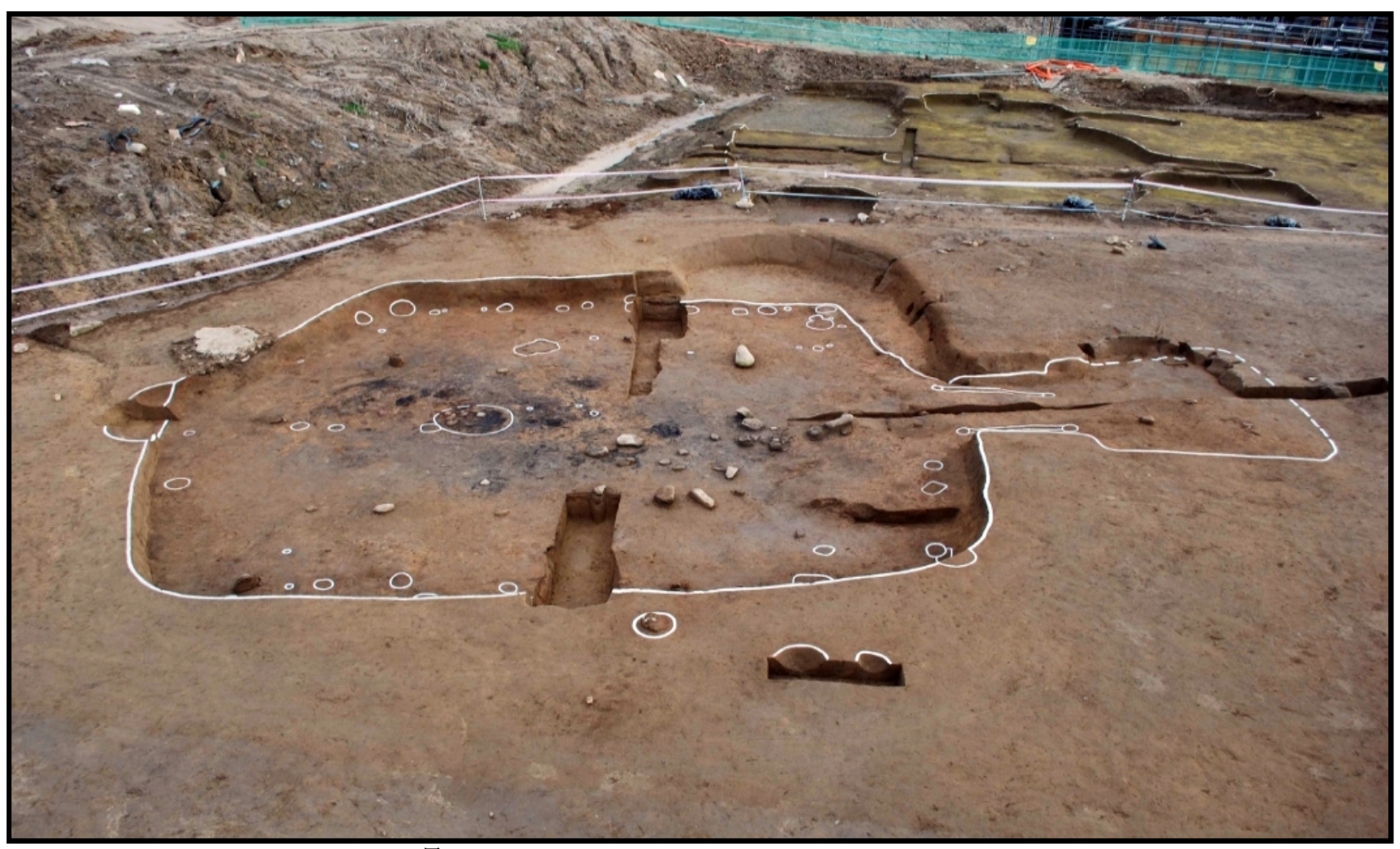

Figure 3: Typical 吕 shaped house from The Iron Age at Eupha-Ri site (Wang et al. 2013).

et al. 2011; Reber and Evershed 2004). In this research we report on a test of the application of both methods.

Gas Chromatography - Mass Spectrometry (hereafter, GC-MS) is used to identify compounds that may be found in a limited number of situations. Such 'biomarkers' can help scientists to reconstruct the dietary life of prehistoric peoples (Evershed 2008a; Evershed 2008b; Heron and Evershed 1993: 276-270). These classes of biomarkers are present in different types of fats; for example, short chain fatty acids in dairy fat, long-chain $\omega$-(o-alkylphenyl)alkanoic acids in fish oil, unsaturated fatty acids in plant oil, cholesterol in animal fat and plant sterols (e.g. b-sitosterol) in plant oil.

Compound Specific Isotope Analysis (hereafter CSIA) can help us to further clarify the origin of the organic compounds in a pot. With the introduction of Gas Chromatography-Combustion-Isotope Ratio Mass Spectrometry (hereafter GC-C-IRMS), the stable carbon isotope values of individual compounds in a mixture can now be measured with high precision.

Even if organic compounds are highly degraded due to the post depositional processes, CSIA can measure the stable carbon isotope (hereafter $\delta 13 \mathrm{C}$ ) value of two most common fatty acids in archaeological pots: palmitic (C16:0) and stearic (C18:0) acids. Generally, different types of food groups tend to have different ranges of $\delta 13 \mathrm{C}$ values of $\mathrm{C} 16: 0$ and $\mathrm{C} 18: 0$ fatty acids. For example, $\delta 13 \mathrm{C}$ values of ruminant (goat, sheep and cow/buffalo), chicken, equine, pig fats, ruminant milk, C3 plants, C4 plants, and aquatic resources (e.g. fish and mammals), have each their own range. Though these values were obtained from the modern fauna and flora, they have been reliably employed as references for many archaeological studies (Craig et al. 2011; Cramp et al. 2011; Fraser et al. 2012; Reber and Evershed 2004).

\section{SITE DESCRIPTIONS}

The pottery samples were collected from two different habitation sites from the central part of the Korean Peninsula; Kimpo-Yangchon site and Eupha-Ri site. Kimpo-Yangchon site is located on the low hillocks of Kimpo city, Gyeonggi province (Figure 1). The site was excavated from 2007 to 2011 by the Korea Institute of Heritage (B. Kim et al. 2013). A total of 126 longhouses (Figure 2), pit features, firing features were excavated. House pits are classified into three types based on their shape; square, rectangular, and longhouse. Considerable amount pottery, ground stone harvesting tools, arrowheads, daggers, and axes were excavated. Based on 14 published AMS radiocarbon dates (B. Kim et al. 2013), the main habitation period of the site was placed around 2800 BP (Early Bronze Age).

The Eupha-Ri site is located in Hoengseong city, Gangwon province (Figure 1). It was excavated during 2009-2011 by the Yonsei University museum (H. Wang et al. 2013). It turned out to be a large-scale habitation site of Iron Age $\sim$ Proto Three Kingdom period which includes a total of 45 houses (Figure 3), abundant pottery, spindle whorls, net sinkers, clay molds. Based on four published AMS radiocarbon dates $(\mathrm{H}$. Wang et al. 2013) and the relative chronology built on pottery and 
the shape of the households, the site's main occupation period is dated to around $1,800 \mathrm{BP}$.

\section{METHODS}

\section{Sampling}

As a preliminary assessment of the feasibility of this approach, four potsherds were collected from each of the sites (total eight samples: Figure 4). To maximize coverage of all aspects of subsistence, all samples were collected from different houses. Our selection of specific parts of the vessel was informed by previous research that has demonstrated that rim or upper body parts are the most useful for organic residue analysis. Baker et al (2011) and Eerkens (2007) have experimentally demonstrated that the rim and upper body parts are the most concentrated in organic residues after cooking. According the ethnographic observations, generally, hightemperature boiling is regarded as particularly effective cooking method in the preparation of faunal and floral resources in pots (Crown and Wills 1995; Stahl 1989; Wandsnider 1997). During this process, convection currents of boiling water pushes extracted lipids from food stuffs to the pot wall. Since lipids float on the water, they tend to accumulate and penetrate into the pot wall of rim and upper body. All eight samples included in this project were rim or upper body parts.

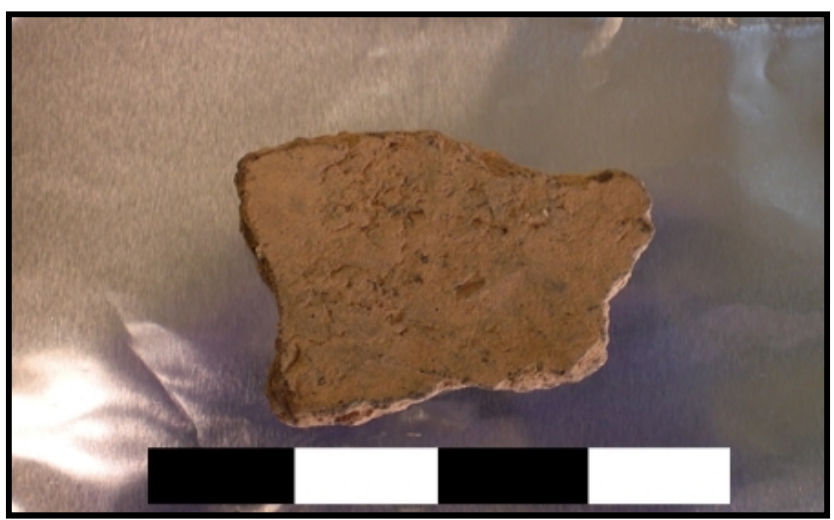

Figure 4: One of the potsherds from Kimpo-Yangchon site sampled for the organic geochemical analyses.

\section{Glassware and solvents}

High performance liquid chromatography (HPLC) grade solvents were used in all experiments. All glassware was wrapped with clean aluminum foil and heat treated at $450^{\circ} \mathrm{C}$ for $24 \mathrm{~h}$ prior to use. Analytical blanks were prepared with each sample batch to identify possible sources of contamination.

\section{Lipid extraction of archaeological potsherds}

We generally followed the analytical procedure of Reber and Evershed (2004). About $5 \mathrm{~g}$ of potsherd surface was cleaned using a modelling drill to remove possible contamination during the process of curation then ground to a fine powder in mortar and pestle. The powdered samples were weighed and transferred to a clean glass test tube. $10 \mathrm{~mL}$ of $\mathrm{CHCl} / \mathrm{MeOH}(2: 1)$ solvent was added to each powdered samples and ultrasonication ( $2 \times 20 \mathrm{~min})$ was applied. The extracted lipids were transferred to test tubes and centrifuged (2500 RPM) for $10 \mathrm{~min}$. The solvent was evaporated under the nitrogen gas to obtain the total lipid extract (hereafter TLE). The one half of TLE was silylated using BSTFA for high temperature GC-MS analysis. The other half of TLE was hydrolyzed with $5 \mathrm{~mL}$ of 0.5 $\mathrm{M} \mathrm{NaOH}$ in $\mathrm{MeOH} / \mathrm{H} 2 \mathrm{O}(9: 1)$ solution. The neutral fraction was extracted with hexane $(2 \mathrm{~mL})$. Then the solution was acidified with $1 \mathrm{M} \mathrm{HCl}$. The fatty acids were then extracted with chloroform $(2 \mathrm{~mL})$. Finally, with extracted fatty acid fraction, the fatty acid methyl esters (FAMEs) were prepared for CSIA.

\section{Gas Chromatography - Mass Spectrometry}

Trimethylsilylated TLEs were analyzed with a 6890N Network GC system with a 5979 Mass selective Detector from Agilent Technologies at the Sachs laboratory, Department of Oceanography, University of Washington. The GC was equipped with a fused silica capillary column (J\&W; DB5-MS; 60m x $0.32 \mathrm{~mm}$; $0.25 \mu \mathrm{m}$ film thickness) and the interface was maintained at $110{ }^{\circ} \mathrm{C}$. The mass spectrometer was operated in full scan mode. Helium was the carrier gas and the GC oven was programmed as follows: 2 min isothermal at $50^{\circ} \mathrm{C}$ followed by an increase to $350^{\circ} \mathrm{C}$ at a rate of

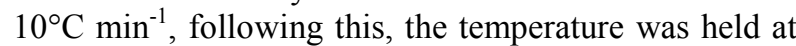
$350^{\circ} \mathrm{C}$ for $10 \mathrm{~min}$. Peaks were identified based on their mass spectral characteristics and GC retention times and also by comparison with NIST mass spectral library.

\section{Compound specific isotope analysis}

For the Compound Specific Isotope Analysis, extracted and dried samples were sent to the Stable Isotope facility at the University of California-Davis. CSIA Analysis (measured ten times) was performed using a Thermo GC/C-IRMS system composed of a Trace GC Ultra gas chromatograph (Thermo Electron Corp.) coupled to a Delta V Advantage isotope ratio mass spectrometer through a GC/C-III interface (Thermo Electron Corp.). Compound identification support for the CSIA laboratory is provided by a Varian CP3800 gas chromatograph coupled to a Saturn 2200 ion trap MS/MS (Varian, Inc.). FAMEs dissolved in hexane are injected in splitless mode and separated on a Varian factor FOUR VF-5MS column (30m X $0.25 \mathrm{~mm}$ ID, $0.25 \mathrm{mi}-$ cron film thickness). FAMEs are quantitatively converted to $\mathrm{CO}_{2}$ in an oxidation reactor at $950^{\circ} \mathrm{C}$. Following water removal through a nafion dryer, $\mathrm{CO}_{2}$ enters the IRMS. $\delta^{13} \mathrm{C}$ values are corrected using working standards composed of several FAMEs calibrated against NIST standard reference materials.

The data produced by these analyses is openly available at [http://dx.doi.org/10.6084/m9.figshare.1288710]. 


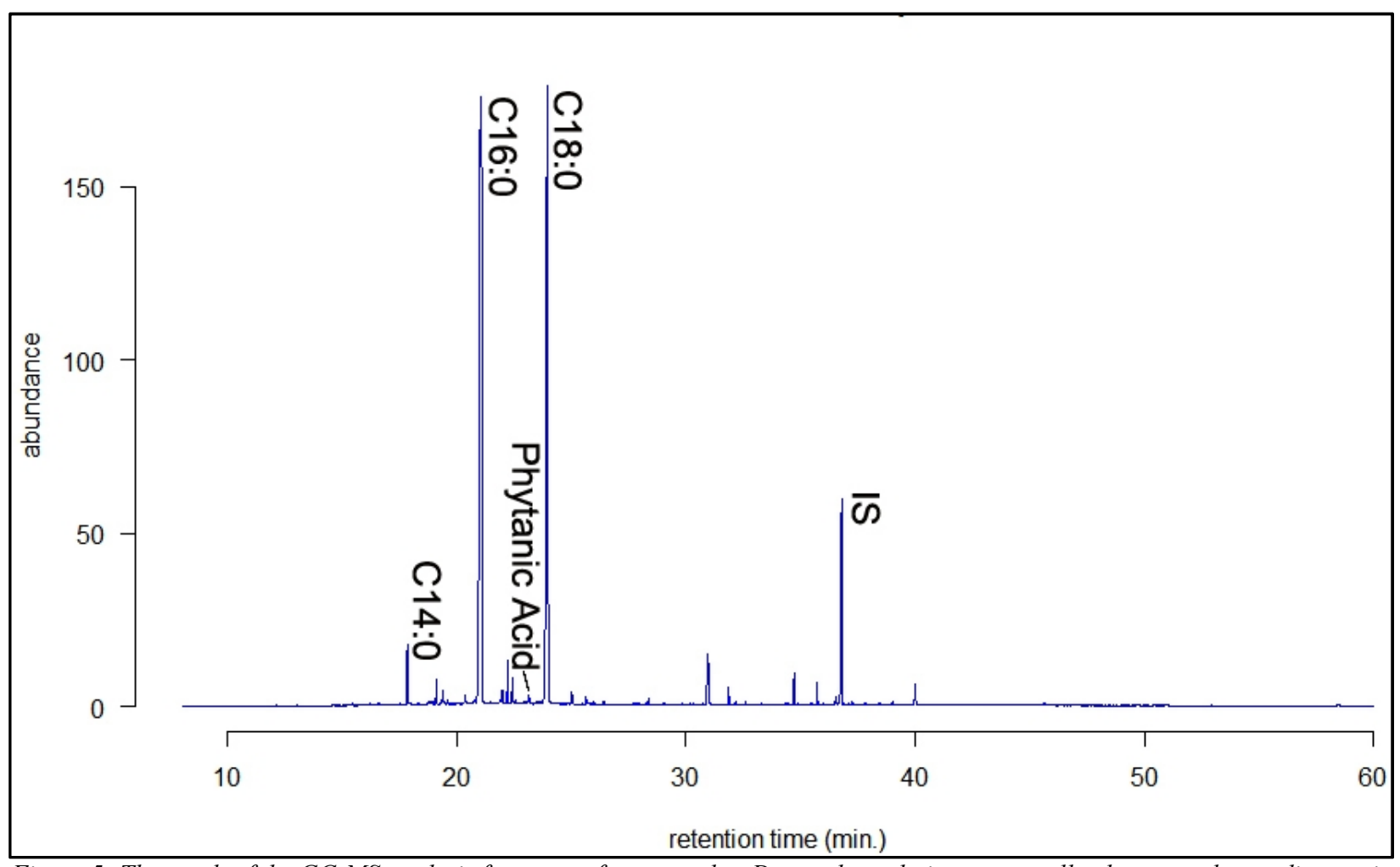

Figure 5: The result of the GC-MS analysis from one of our samples. Due to degradation, we usually observe rather undiagnostic C16:0 and C18:0 fatty acids. IS: Internal standard (5 $\alpha$-cholestene).

\section{RESULTS AND DISCUSSION}

In many cases, the most frequently observed compounds in archaeological lipid residue are palmitic (C16:0) and stearic (C18:0) fatty acids (Evershed 2008a). As expected, organic compounds of all samples were dominated by those two saturated fatty acids (Figure 5). This means the samples were highly degraded in soil during several thousand years of post-depositional processes. In order to try to get a better signal from the compounds which may be present only in very low quantities due to severe degradation, or which may be masked by more abundant compounds such as C16:0 and C18:0 fatty acids, it has been suggested to run GCMS with selective ion monitoring mode (hereafter SIM). Since the primary purpose of this project was to explore the potential of organic geochemical analyses in contexts where zooarchaeological assemblages are small or unavailable, running GC-MS with SIM was not included in this study. However, we will include this approach for our future studies. With the result of GCMS analysis, we were able to identify both short- and long-chain (un)saturated fatty acids including C14:0, C16:0, C17:0, C18:0, C18:1, C20:0, C22:0 and C23:0. Beside those fatty acids, the most interesting compund that we have detected is phytanic acid $(3,7,11,15$ tetramethylhexadecanoic acid) (Figure 5). Phytanic acid (3,7,11,15-tetramethylhexadecanoic acid) and 4,8,12TMTD (4,8,12-trimethyltridecanoic acid) are isoprenoid compounds that mostly found in particularly high concentrations in marine animals (Evershed et al. 2008). Along with thermally produced long-chain $\omega-(0-$ alkylphenyl)alkanoic acids, these compounds are indicators of aquatic/marine resources (Craig et al. 2011; Evershed et al. 2008). Among eight samples in this study, we were able to observe phytanic acid from two samples (one from Kimpo-Yangchon, the other from Eupha-Ri). Though long-chain $\omega-(0-$ alkylphenyl)alkanoic acids were not identified, it is possible that those two pots were used for processing aquatic resources. According to the isotopic studies on bones from coastal shell middens (Choy and Richards 2010; Choy et al. 2012), the diet of Neolithic foragers of Korean Peninsula was dominated by marine products. Considering the age of samples in this study (Bronze Age and Iron Age), our results indicate that ancient Koreans might have continued to rely on aquatic resources well after intensive agriculture was introduced.

Further CSIA was applied for C16:0 and C18:0 fatty acids to clarify the origin of organic compounds in the samples. When conducting CSIA, the typical way to establish the reference database is to collect modern samples of fauna and flora from the same region where archeological materials were collected. However, modern commercial farming with chemical supplements makes it impossible for us to directly compare $\delta^{13} \mathrm{C}$ values from archeological materials with those from modern samples. To overcome this issue, samples were collected from wild fauna and flora for creating the reference database (Craig et al. 2011; Copley et al. 2003; Dudd and Evershed 1998; Dudd et al. 1999; Steele, Stern, and Stott 2010). Unfortunately, in case of 


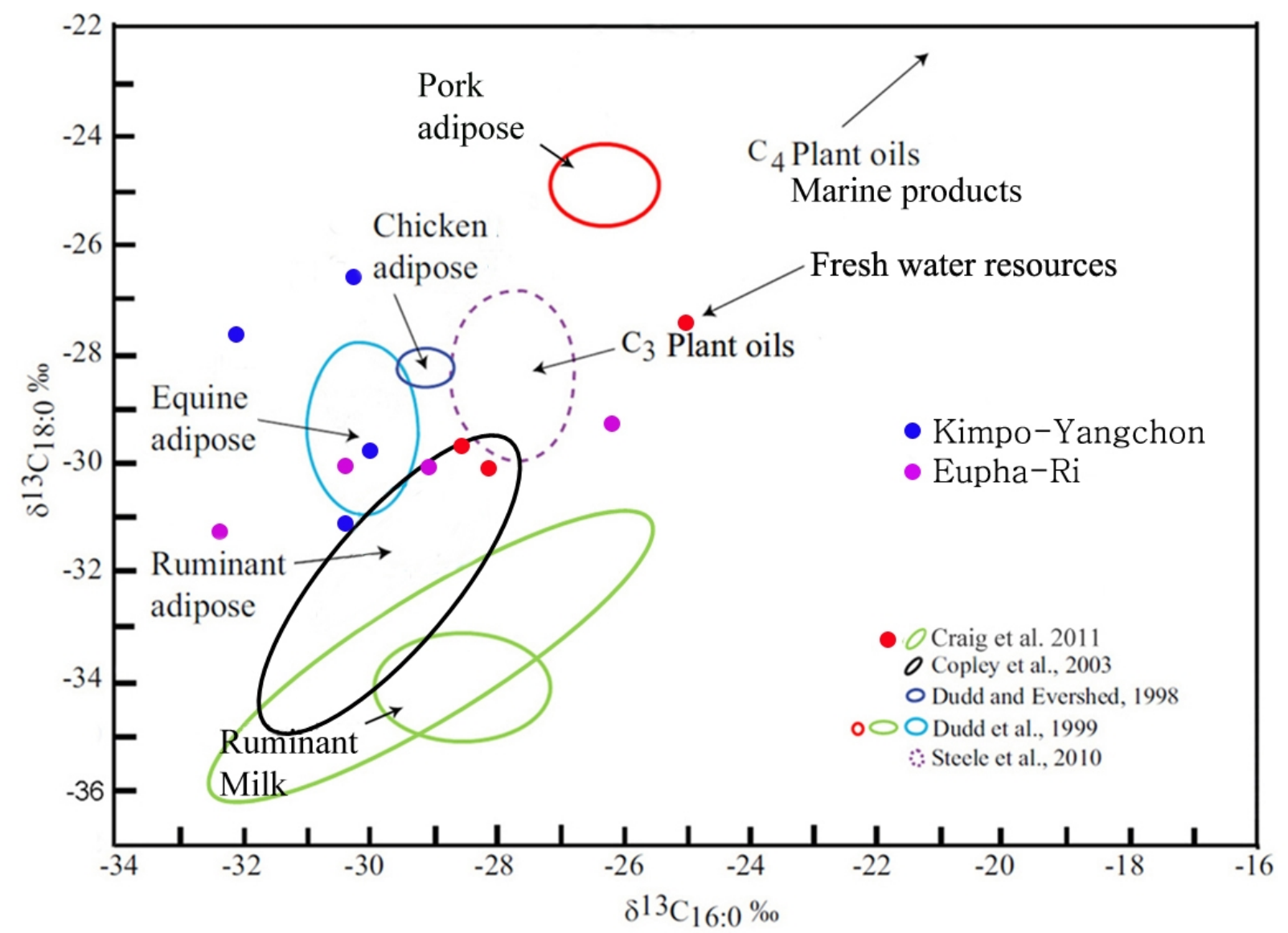

Figure 6: The result of the CSIA. Blue dots are samples from Kimpo-Yangchon site and violet ones are from Eupha-Ri site. (Modified from Fraser et al. 2012).

Korea, wild terrestrial mammals are extremely rare, so here we rely on reference data from other regions.

Here we take the stable carbon isotope values of C16:0 and C18:0 fatty acids from the archaeological samples and compare them with the available modern references that were obtained from the modern fauna and flora that exist in either Western Europe or North America (Craig et al. 2011; Copley et al. 2003; Dudd and Evershed 1998; Dudd et al. 1999; Steele, Stern, and Stott 2010) to detect the presence of the potentially cooked resources. Since almost all the fauna and flora having produced the data for reference exist also in the Korean Peninsula, this approach assumes that the $\delta^{13} \mathrm{C}$ values of available modern samples from Western Europe and North America are comparable to archaeological ones from the Korean Peninsula.

Figure 6 shows the result of the CSIA. The result indicated that most of the pots were used for processing terrestrial mammals (e.g. ruminants). There was one exception, which was probably used for cooking $\mathrm{C}_{3}$ plants. Summing up, the results from GC-MS analysis and CSIA showed the possibility that the pots were used to process both terrestrial and aquatic animals.

As we noted above, because of the high acidity of sediment in Korean Peninsula, the direct examination of the remains of resources in the Korean Peninsula is limited to relatively special locations that provide better preservation of bone or plant remains such as cave, rock-shelters, or shell middens. Due to these reasons, the importance of both terrestrial and aquatic animal foods in the ancient Korean famers' diet during this period was undermined when interpreting large-scale inland habitation sites such as Kimpo-Yangchon and Eupha-Ri.

However, our results suggest that both terrestrial and aquatic animals also might have been part of the ancient farmers' diet, well after farming was introduced. Though it is unquestionable that intensive agriculture was practiced in Korean Peninsula since the Early Bronze Age (G. Lee 2003; 2011), our results indicate that there was a wider range of resource utilization and the role of mammals in diet and resource management may have been underestimated in previous research.

Whether the detected equine and ruminant fats came from wild terrestrial animals or domesticated ones is a different question. Given the fact that the comparative reference compounds were created based on present day wild animals, we assume, but cannot prove, that the detected fats were from wild ones and hunting persisted alongside agriculture. Also, as G. Lee (2011) pointed out, most reports on domesticated animals from ancient Korean Peninsula are controversial because both the criteria for domestication and the context of discovery are unclear. However, we cannot total eliminate the 
possibility that the tamed traction animals for farming can contribute to the lipid residue. Further work is required to determine the reliability of this assumption and the dietary importance of wild versus domesticated fauna.

Our small sample size clearly limits the generality of our results to the question of the dominant subsistence behaviors of ancient farmers that lived in the central part of the Korea Peninsula. In addition to that, we have to admit that this type of approach cannot reflect the entire subsistence during the period in question, for boiling food inside of a pot is not the only option for food preparation. The most important implication of this preliminary analysis is that through this attempt, we have been able to see the potential of organic geochemical analyses in contexts where zooarchaeological assemblages are small or unavailable due to poor preservation. We expect this approach will be widely applicable to questions of ancient human subsistence elsewhere in East Asia, Southeast Asia, and the Pacific, especially the areas with harsh environments that do not favor long-term preservation of macroscopic plant and animal remains.

\section{CONCLUSION}

The purpose of this study was to conduct an exploratory analysis of the organic compounds preserved in the fabric of the ceramics from the prehistoric Korean Peninsula. We have shown that terrestrial mammals appear to have been an important part of the diet, suggesting that these food classes in ancient Korean farmers have been underestimated in the absence of a substantial faunal record. However, since our results were from only eight potsherds, we must be cautious about generalizing to whole features of the two sites and beyond. Nevertheless, the results provided a promising clue for a further interpretation of the usage patterns of the pottery, and challenge existing notions of the dietary patterns of the ancient people in the central part of the Korean Peninsula.

\section{ACKNOWLEDGEMENTS}

This research was partially funded by NSF DDIG Grant \# 1349747. We thank Dr. Rick Keil, Dr. Julian Sachs and Daniel Nelson for their assistance with GC-MS and CSIA. We also thank Dr. Byung-mo Kim, Dr. KyeongTaek Kim, Dr. Tae-sop Cho, and Dr. Sujin Kong for providing potsherd samples. We also Thank Dr. Peter Lape and Dr. James Feathers for comments on NSF DDIG proposal. Thanks to three anonymous reviewers for helpful comments that improved the manuscript.

\section{REFERENCES}

Choy, K. and M.P. Richards 2010. Isotopic evidence for diet in the Middle Chulmun period: a case study from the Tongsamdong shell midden, Korea. Archaeological and Anthropological Sciences 2: 1-10.

Choy, K. et al. 2012. Stable isotopic analysis of human and faunal remains from the Incipient Chulmun (Neolithic) shell midden site of Ando Island, Korea. Journal of Archaeological Science 39: 2091-2097.

Copley, M.S. et al. 2003. Direct Chemical Evidence for Widespread Dairying in Prehistoric Britain. Proceedings of the National Academy of Sciences 100: 1524-1529.

Craig, O.E. et al. 2011. Ancient Lipids Reveal Continuity in Culinary Practices across the Transition to Agriculture in Northern Europe. Proceedings of the National Academy of Sciences 108: 17910-17915.

Cramp, L.J. et al. 2011. What Was a Mortarium Used for? Organic Residues and Cultural Change in Iron Age and Roman Britain. Antiquity 85: 1339-1352.

Crown, P.L. and W.H. Wills 1995. The Origins of Southwestern Ceramic Containers: Women's Time Allocation and Economic Intensification. Journal of Anthropological Research 51: 173-186.

Dudd, S.N. and R.P. Evershed. 1998. Direct Demonstration of Milk as an Element of Archaeological Economies. Science 282: 1478-1481.

Dudd, S.N. et al. 1999. Evidence for Varying Patterns of Exploitation of Animal Products in Different Prehistoric Pottery Traditions Based on Lipids Preserved in Surface and Absorbed Residues. Journal of Archaeological Science 26: 1473-1482.

Eerkens, J.W. 2001. The Origins of Pottery among Late Prehistoric Hunter-Gatherers in California and the Western Great Basin. Ph.D. dissertation. University of California Santa Barbara.

Eerkens, J.W. 2005. GC-MS Analysis and Fatty Acid Ratios of Archaeological Potsherds from the Western Great Basin of North America. Archaeometry 47: 83-102.

Evershed, R.P. 2008a. Experimental Approaches to the Interpretation of Absorbed Organic Residues in Archaeological Ceramics. World Archaeology 40: 26-47.

Evershed, R.P. 2008b. Organic Residue Analysis in Archaeology: The Archaeological Biomarker Evolution. Archaeometry 50: 895-924.

Evershed, R.P. at al. 2008. Experimental Evidence for the Processing of Marine Animal Product And Other Commodities Containing Polyunsaturated Fatty Acids in Potter Vessels. Archaeometry 50: 101-113.

Fraser, S.E. et al. 2012. Organic Geochemical Analysis of Archaeological Medicine Pots from Northern Ghana. The Multi-Functionality of Pottery. Journal of Archaeological Science 39: 2506-2514.

Heron, C. and R.P. Evershed. 1993. The Analysis of Organic Residues and the Study of Pottery Use. Archaeological Method and Theory 5: 247-284.

Heron, C. et al. 1991. Effects of Migration of Soil Lipids on Organic Residues Associated with Buried Potsherds. Journal of Archaeological Science 18: 641-659.

Kim, B. C. 2006. Political Economy of Wet Rice Cultivation in the Bronze period in Central Western Korea. Journal of the Korean Archaeological Society 58: 40-65. (In Korean).

Kim, B. M. et al. 2013. Kimpo-Yangchon site. Hanam: The Korea Institute of Heritage. (In Korean).

Kim, J. C. et al. 2010. Re-Evaluation of the Chronology of the Palaeolithic Site at Jeongokri, Korea, Using OSL and TT-OSL Signals from Quartz. Quaternary Geochronology 5: 365-370. 
Lee, G.-A. 2003. Changes in subsistence patterns from the Chulmun to Mumun periods: archaeobotanical investigation. Ph.D. dissertation. University of Toronto.

Lee, G.-A. 2011 The Transition from Foraging to Farming in Prehistoric Korea. Current Anthropology 52: S307S329.

Reber, E.A. and R.P. Evershed. 2004. How Did Mississippians Prepare Maize? The Application of CompoundSpecific Carbon Isotope Analysis to Absorbed Pottery Residues From Several Mississippi Valley Sites. Archaeometry 46: 19-33.

RDA 1988. Technical report on Korea soil. Rural development Administration (RDA) of Republic of Korea. (In Korean).

Stahl, A.B. 1989. Plant-food processing: implications for dietary quality. In eds. D. R. Harris and G. C. Hillman. Foraging and farming: the evolution of plant exploitation. pp. 171-94. London: Unwin Hyman.

Steele, V.J. et al. 2010. Olive Oil or Lard?: Distinguishing Plant Oils from Animal Fats in the Archeological Record of the Eastern Mediterranean Using Gas Chromatography/combustion/isotope Ratio Mass Spectrometry. Rapid Communications in Mass Spectrometry 24: 3478-348.

Wandsnider, L. 1997. The Roasted and the Boiled: Food Composition and Heat Treatment with Special Emphasis on Pit-Hearth Cooking. Journal of Anthropological Archaeology 16: 1-48.

Wang, H.J. et al. 2013. Excavation report of the potential Hoengseong leisure park ground plot. Seoul: Yonsei University museum. (In Korean).

Yoon, T.Y. and J.S. Bae. 2010. Agrarian society and the leader. Seoul: National museum of Korea. (In Korean). 